\title{
NEW MODEL FOR ORTHORECTIFICATION OF EGYPT SAT-1 IMAGES
}

\author{
Yasser G. Mostafa ${ }^{a}$, Farrag A. Farrag ${ }^{b}$, Ahmed A. \\ Abdelhafiz ${ }^{c}$, and Abdelaal M. Abd Elwahed ${ }^{c}$ \\ ${ }^{a}$ Civil Eng. Dpt. Faculty of Engineering, Sohag University. \\ ${ }^{b}$ Civil Eng. Dpt. Faculty of Engineering, Aljouf University, KSA. \\ ${ }^{c}$ Civil Eng. Dpt. Faculty of Engineering, Assiut University.
}

(Received October 27, 2011 Accepted December 20, 2011)

\begin{abstract}
Digital orthoimages are proving to be suitable for a variety of mapping, Geographic Information Systems (GIS) and environmental monitoring tasks. The quality of the extracted data from orthoimages depends mainly on the accuracy of the input data and the used mathematical models. The availability of the Egypt Sat-1 satellite images provide valuable source of remote sensing data in Egypt. Egypt Sat-1 is the first Egyptian earth observation satellite which was successfully put in orbit on 2007. The main aim of this research is to represent a rigorous sensor model approach applied to Egypt Sat-1 image for orthoimage productions. For this study an image level 1A from Egypt Sat-1 satellite captured in 2009 and a topographic map, dated 1991, at scale 1:25,000 of the region of Assiut city and the surrounding are used.

Orthoimage are generated in two parallel stages. The first stage is generation of Digital Elevation Model (DEM) and the second stage is developing mathematical model for an image-to-object relationship. The results of these two stages are integrated to generate the orthoimage proposed in two steps. The first step is the determination of image coordinates (in the original image plane) corresponding to the DEM grid points. The second step is assigning a gray value for these pixels. The results of this study demonstrate the possibility to orthorectify Egypt Sat-1 images to sub-pixel accuracy. Orthoimages that were generated from Egypt Sat-1 satellite images can contribute significantly to image map production and to GIS applications.
\end{abstract}

KEYWORDS: Egypt Sat-1, DEM, Orientation, Orthoimage.

\section{INTRODUCTION}

Satellite images generally have geometric distortions. These distortions mainly are caused by the earth curvature, earth rotation, satellite attitude, satellite altitude, geometric characteristics of sensor, etc. Each image acquisition system produces unique geometric distortions in its raw images (Toutin, 2004). These distortions must be modeled and corrected by using a specific mathematical model. Satellite is moving along a well defined close-to-circular elliptical orbit and sensor is always pointing to the centre of the earth. A single image taken with a pushbroom scanner sensor consists of a fixed number of consecutive scan lines in a constant time interval. Each line has its own time-dependent position and attitude parameters (exterior orientation). Despite of 
the dynamic character of the image orientation, not all parameters of the exterior orientation can be reconstructed for each line, but these parameters are highly correlated for neighboring lines. Assume the satellite obeys Kepler's laws and moves along an orbital ellipse. The orbit can be described by the six Keplerian parameters (Fritsch and Stallmann, 2000). These parameters define an ellipse, and orient it in relation to the earth and place the satellite on the ellipse at a particular time. The sensor position can be derived from known nominal orbit relations, while the attitude variations are modeled by a simple polynomial model (linear or quadratic).

Generating an orthoimage from satellite images is an important undertaking for various remote sensing and photogrammetric applications. Orthorectified images are planimetrically true images that represent ground objects in their true "real world" $\mathrm{X}$ and $\mathrm{Y}$ positions. Figure 1 shows the method used to generate the orthoimage described in this paper. As indicated in the diagram, stage 1 provides the methodologies for generating DEM, while stage 2 leads to the development of mathematical model. When the results in stages 1 and 2 are integrated, resampling is carried out to generate the orthoimage.

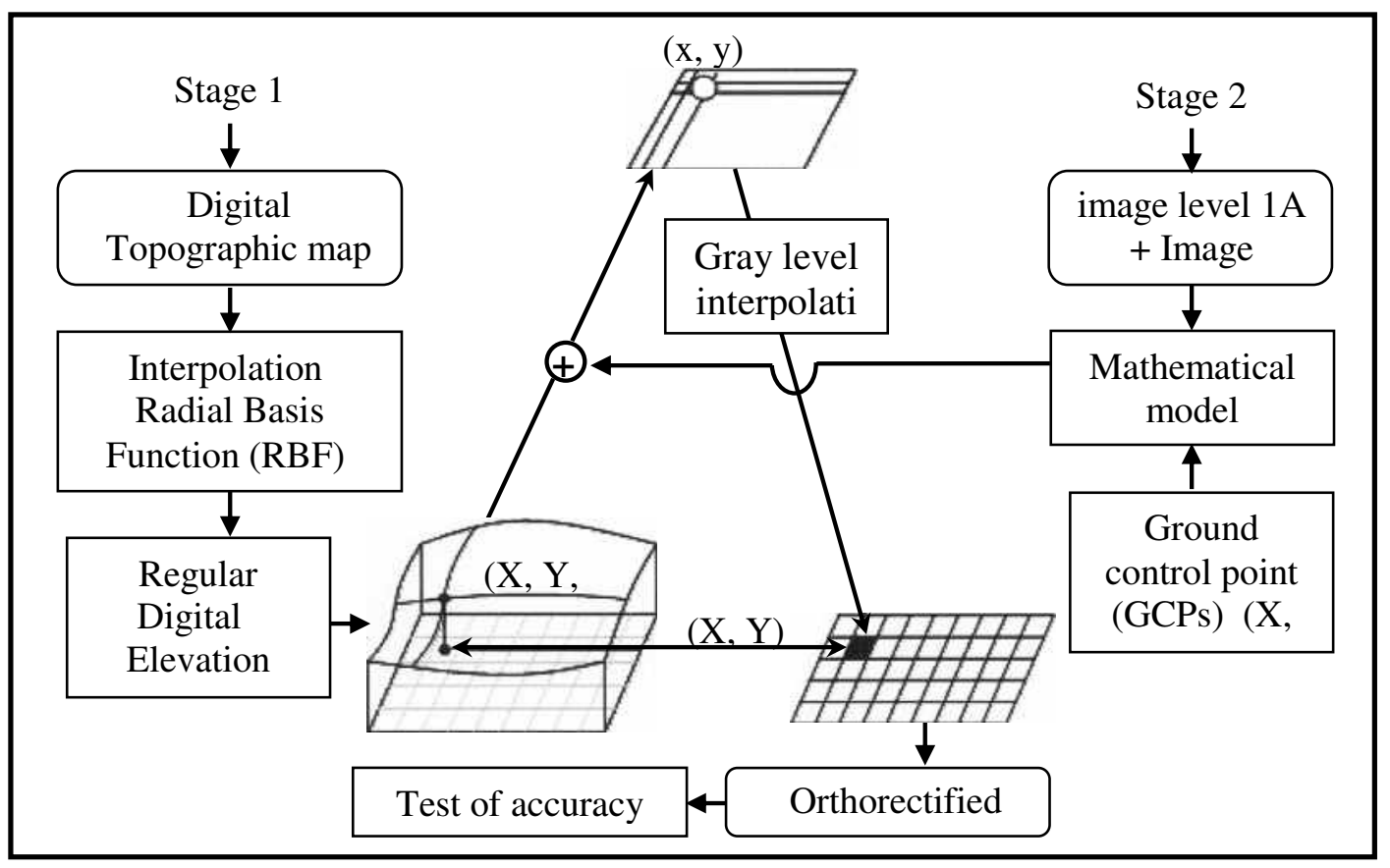

Figure 1: General flowing diagram for orthoimage generation.

The aim of this research is to represent rigorous sensor model that depicts geometric relationship between the image coordinates and the corresponding ground coordinates for production of orthoimage by using Egypt Sat-1 satellite image level 1A. In order to achieve the aim of this research the following steps were performed:

1. Development of a mathematical model to describe the relationship between Egypt Sat-1 image and ground coordinates.

2. Generation of DEM data from existing 1:25,000 map. 

3. Measurement of a series of check points to assess the accuracy of produced orthoimage.
4. Generation of orthoimage.

\section{STUDY AREA AND DATA SETS}

\subsection{Egypt Sat-1:}

Egypt Sat-1 (also referred to as Misrsat-1) is an international collaborative microsatellite project of NARSS (National Authority for Remote Sensing and Space Science) of Egypt and the Yuzhnoye State Design Office (YSDO), Dnepropetrosvk, Ukraine. Egypt Sat-1 satellite can capture a vertical image for any location in Egypt once every 75 days. It also can be tilted to capture images for location at both sides of satellite path, capture stereo images, or re-capture images for location within periods less than 16 days (NARSS, 2011). Egypt Sat-1 was launched into a sun-synchronous, at an altitude of $668 \mathrm{~km}$ above the earth surface, inclination about 98.1 degree with equator and 98 minute orbital period .The satellite carries a $7.8 \mathrm{~m}$ ground resolution optical scanner which images in 3 spectral bands and a panchromatic band with $46 \mathrm{~km}$ image swath. Spectral resolution of the satellite are $0.51-0.59 \mu \mathrm{m}$ "Green band", 0.61 - $0.68 \mu \mathrm{m}$ "Red Band", $0.80-0.89 \mu \mathrm{m}$ "Near Infrared band" and $0.50-0.89 \mu \mathrm{m}$ "Panchromatic band" (Ayman and Ashraf, 2009). The satellite also carries a near infrared scanner with a resolution of $39.5 \mathrm{~m}$, spectral resolution of $1.51-1.70 \mu \mathrm{m}$ and $55 \mathrm{~km}$ image swath.

\subsection{Study Area:}

The study area is located in the central of the governorate of Assiut. It includes the city of Assiut ('A' in Figure 2), and the other urban areas presented in the area include several scattered villages around the city. The Nile River illustrated as ' $B$ ' in Figure 2 extends from the right to the left of the study area and Ibrahimya Canal crosses the Assiut city. The area also contains several randomly distributed small canals. The mountainous areas represented as ' $\mathrm{C}$ ' are located in the south western part of the city of Assiut and the rest of the study area is characterized by agricultural areas, which are represented as ' $\mathrm{D}$ '. The elevations range from approximately $50 \mathrm{~m}$ above sea level for the flat areas to $240 \mathrm{~m}$ above sea level for the mountainous areas yielding a total relief around $190 \mathrm{~m}$.

\subsection{Data Sets:}

Data used in this study are multispectral satellite image from Egypt Sat-1 satellite and topographic map. Egypt Sat-1 image captured in August 26, 2009, level 1A with $7.8 \mathrm{~m}$ spatial resolution. Figure 2 shows the false color composite image for study area. Topographic map at scale 1:25,000 (the only available map for the study area) compiled from aerial photographs at 1991 (Figure 3) covering the study area with contour intervals of $10 \mathrm{~m}$. Topographic map was used for selecting the Ground Control Points (GCP), and to generate the DEM. 


\subsection{Software Used:}

Golden Software Surfer 9.0 program software was used to generate regular DEMs grid from contour data of 1:25,000 scale digital map. Special computer programs were developed in visual basic 6 language by the author for satellite orbital modeling and carrying out the resampling algorithms for the generation of orthoimage from Egypt Sat-1 image. Selecting ground control points, check points and final preview for the orthoimage were carried out using ERDAS Imagine 8.4.

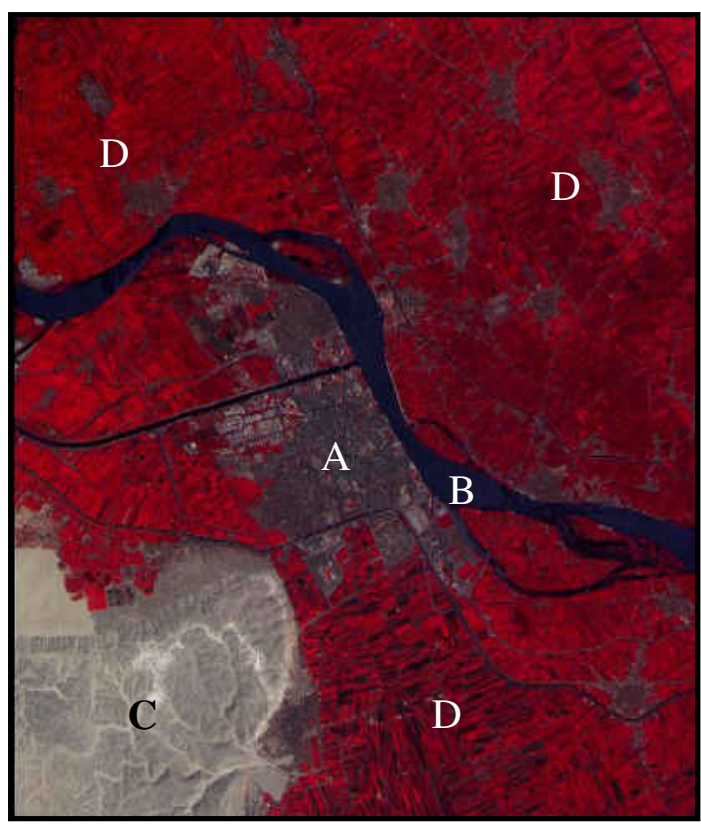

Figure 2: Egypt Sat-1 false color composite image of the study area. (A) Assiut city, (B) Nile River, (C) Mountainous sites, and (D) Agricultural areas.

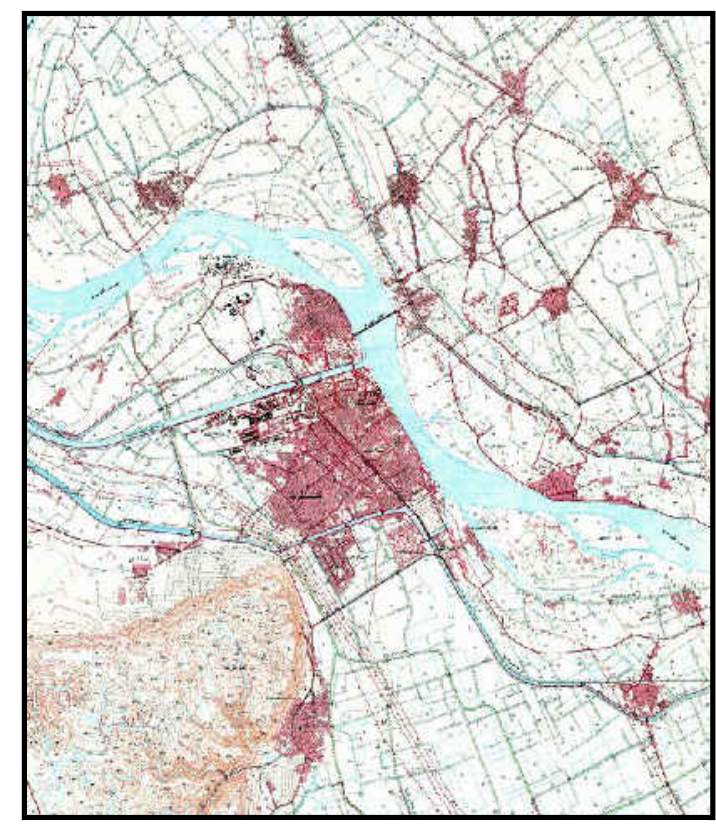

Figure 3: Topographic map 1:25,000 for Assiut city and the surrounding with 10 $\mathrm{m}$ contour intervals.

\section{MATHEMATICAL MODEL}

To generate the orthoimage, a relationship between image coordinates and ground coordinates is required. Each image line of Egypt Sat-1 image is acquired virtually instantaneously, and can be considered to be equivalent to a central perspective image, which covers approximately $46 \mathrm{~km}$ by $7.8 \mathrm{~m}$ on the ground. Egypt Sat-1 image consists of 6000 of these image lines acquired sequentially. The position and the attitude of the sensor are changing continually in a systematic way to keep the satellite pointing towards the centre of the Earth. An orbital resection method was derived to model these changes by finding the orbital parameters of the satellite during the exposure of the image from the orbits.

The initial research assumptions are:

- The coordinates along the flight path have the same scale (constant time interval). 
- The orientation of the satellite images are carried out in a geocentric coordinate system in order to avoid distortions caused by earth curvature and map projection.

- The satellite motion during the acquisition time of images is a Keplerian motion. In combination with the previous assumption, an inertial coordinate system is used.

\subsection{Coordinate Systems Used in the Algorithm:}

\subsection{Image Co-ordinate System:}

The origin of the image co-ordinate system $(\mathrm{x}, \mathrm{y}$ and $\mathrm{z})$ used in this method is positioned at the centre of the scan line which moves along the orbit of the satellite (Figure 4). The $\mathrm{y}$ axis is a parallel to the array of detectors, pointing eastward in a descending pass. The $\mathrm{z}$ axis is perpendicular to the y axis, directed from the scan line along the optical axis in the direction opposite to that of the ground. The $x$ axis completes a right-handed system pointing in the direction of satellite motion (Farrag, 1991, Poli, 2002).

The linear array itself passes through the principal point in the focal plane where the $\mathrm{x}$ coordinate is zero. The $\mathrm{x}$ coordinate of the (6000 line * 6000 pixel) image is the line number of this pixel $(-3000 \leq \mathrm{x} \leq+3000)$ and it is used as a measure of time at which a

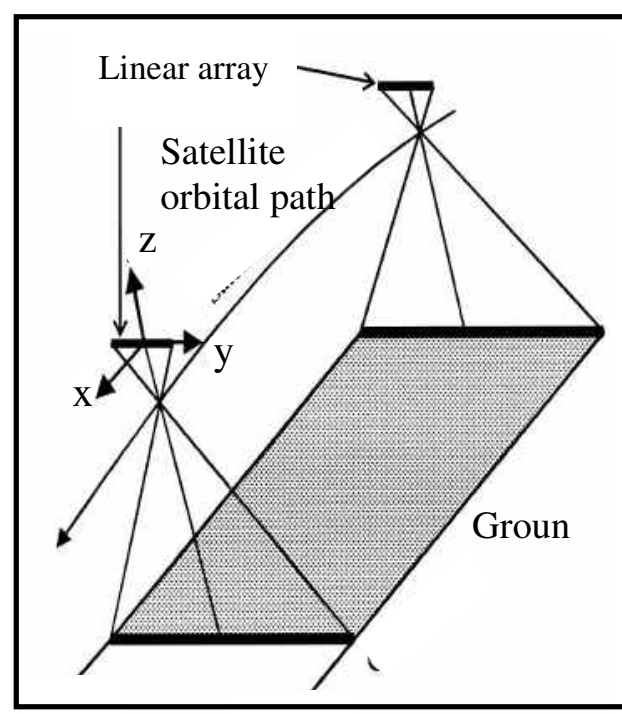

Figure 4: Image co-ordinate system. point was imaged.

\subsubsection{Object Co-ordinate Systems:}

Egypt Sat-1 scene covers a large area of the earth's surface. So to avoid distortions caused by earth curvature and the map projection characteristics, the Geocentric Coordinate System (X Y Z) is used as the working coordinate system. Coordinates of ground control points given in geographical coordinate system will be transformed to the geocentric system.

\subsection{Satellite Orbit Model:}

In order to retrieve accurate geolocation information from satellite images, it is important to have appropriate sensor model. There are many sensor models proposed for satellite images and they can be classified into two categories: rigorous models and generalized models (Kim and Dowman, 2006). The rigorous models employ the physical parameters of sensors and platforms such as focal length, the dimensions of charge-coupled devices (CCDs), satellite orbital parameters or attitude angles within their mathematical representations. Rigorous sensor model is usually the preferred geometric model in photogrammetric applications, because of its power of modeling physical characteristics of the sensor and the imaging setting. However, the rigorous 
sensor model is rather complex and requires specialized software, and sometimes the sensor models and their physical parameters are not made available unintentionally or intentionally (Toutin, 2004). Generalized sensor models usually involve mathematical models that are easier to understand. These models neither use nor require information related to the sensor, platform, the Earth, and do not reflect the physical geometry of the distortions. In this respect, the generalized sensor models require simple mathematical models to relate the object space and the image space (Ok and Turker, 2007). In this research the rigorous model are selected and the following three principles are adopted:

1. The model, as nearly as possible, describes the actual variation of the position and attitude of the sensor with time.

2. The model expresses in terms of a minimum number of variable parameters, to minimize the ground control requirement.

3. Introduce information known a priori about the satellite position and the attitude to reduce a correlation between the parameters.

\subsubsection{Model Description:}

The difference between the frame camera and linear array sensor is that in the frame camera, one image has one set of Exterior Orientation (EO) parameters, while for a linear array sensor, each scan line has its own EO parameters. That is, the EO parameters change from one image line to the other. It is not practical to attempt to derive explicitly the values of the position $(\mathrm{X}, \mathrm{Y}$, and $\mathrm{Z})$ and attitude $(\omega, \varphi$, and $\kappa)$ parameters for each line using ground control points. Changes of EO parameters are often modeled by polynomials. From a computational point of view, solving for polynomial coefficients of the EO parameters in a photogrammetric adjustment instead of actual EO parameters of each image line greatly reduces the required number of GCPs and can achieve a higher computational efficiency (Li, 1998, Zhou and Li, 2000, Ok and Turker, 2006). The principle of an extended bundle solution is applied to the ground control points and their corresponding points in the Egypt Sat-1 image. The photogrammetric standard bundle solution is based on the following space resection formula:

$$
\left(\begin{array}{c}
\mathrm{x} \\
\mathrm{y} \\
-c
\end{array}\right)=\mathrm{s} * \mathrm{M}(\kappa) * \mathrm{M}(\varphi) * \mathrm{M}(\omega) *\left(\begin{array}{c}
\mathrm{X}-\mathrm{X}_{\mathrm{o}} \\
\mathrm{Y}-\mathrm{Y}_{\mathrm{o}} \\
\mathrm{Z}-\mathrm{Z}_{\mathrm{o}}
\end{array}\right)
$$

where:

c is the effective focal length

$\mathrm{s} \quad$ is a scale factor

$\mathrm{x}$ and $\mathrm{y} \quad$ are the photo coordinates of a point

$\mathrm{X}, \mathrm{Y}$ and $\mathrm{Z} \quad$ are the ground coordinates of the same point

$\mathrm{XO}, \mathrm{YO}$ and $\mathrm{ZO}$ are the perspective center coordinates

$\mathrm{M}(\kappa), \mathrm{M}(\varphi)$ and $\mathrm{M}(\omega)$ are orthogonal matrices as a function of rotation angles (kappa, phi and omega) between ground and photo coordinate systems.

The satellite orbit can be described by using the well-known six Keplerian elements. According to Keplerian laws, satellites (considered as material point) under 
the effect of a gravitational field generated by a mass concentrated in a point moving in a plane describing an elliptic orbit which can be represented by six parameters (Giannone, 2006). This set of elements describes an orbital ellipse around the earth and then orients it three dimensionally and places a satellite along the ellipse in time. The elements are the true anomaly $(f)$, orbital inclination $(i)$, argument of perigee $\left(\omega_{\mathrm{p}}\right)$, and right ascension of the ascending node $(\Omega)$ (comprising four of the Keplerian elements). The instantaneous distance of the satellite from the earth's centre (r), which can be computed from the expression $a\left(1-e^{2}\right) /(1+e \cos f)$, where $a$ is the semi-major axis of the elliptical orbit and $e$ is the orbital eccentricity (kratky, 1987). These constitute the remaining Keplerian elements required to define the satellite orbital characteristics as shown in Figure 5. The relationship between the points in the object coordinate system and the corresponding points in the image coordinate system is based on three rotations using combinations of the Keplerian parameters, plus three rotations, $\omega, \varphi, \kappa$, for the additional undefined rotations of the satellite at the time of imaging.

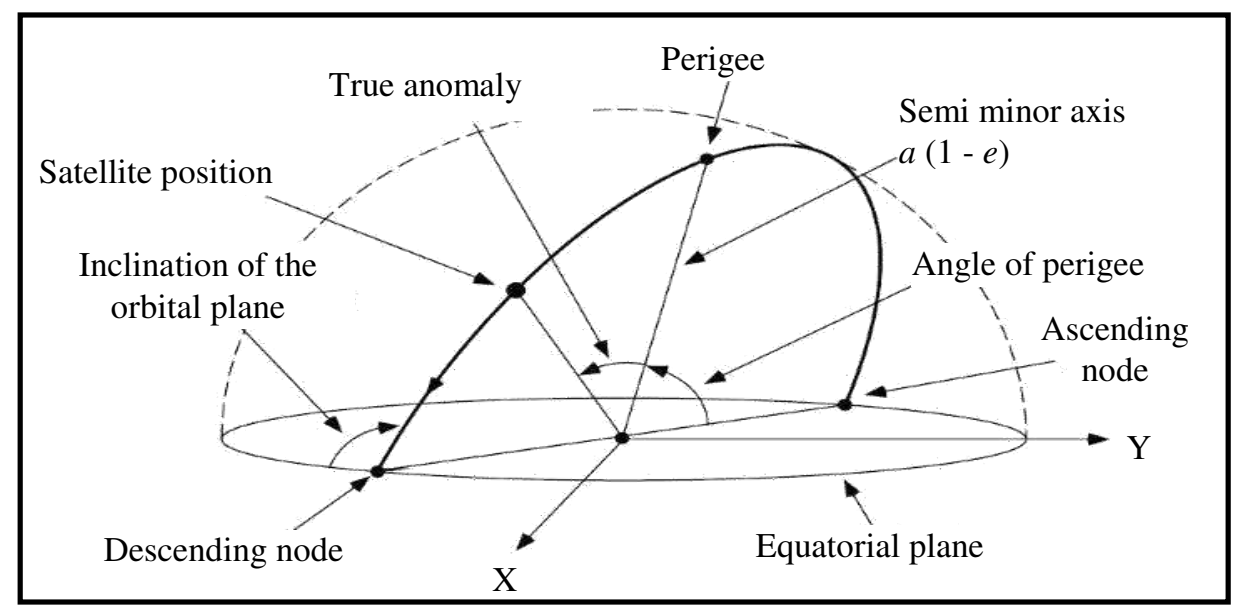

Figure 5: Satellite orbit parameters.

The major components of the dynamic motion are the movement of the satellite in orbit and the earth rotation. These two components are modelled as linear angular changes of $f$ and $\Omega$ with respect to time, defined as $f_{1}$ and $\Omega_{1}$ (Valadan and Petrie, 1998) thus:

$$
\begin{aligned}
& f_{\mathrm{i}}=\left(f_{0}+\omega_{\mathrm{p}}\right)+f_{1} x_{\mathrm{i}} \\
& \Omega_{\mathrm{i}}=\Omega_{0}+\Omega_{1} x_{\mathrm{i}}
\end{aligned}
$$

Where: $f_{\mathrm{i}}$ and $\Omega_{\mathrm{i}}$ are the true anomaly and the right ascension of the ascending node of each line $i$ respectively, $f_{0}$ and $\Omega_{0}$ are the true anomaly and the right ascension of the ascending node with respect to a reference line and $f_{1}$ and $\Omega_{1}$ are the linear rates of change of $f_{\mathrm{i}}$ and $\Omega_{\mathrm{i}}$.

The orbital eccentricity $(e)$ remains very stable for orbiting satellites, so this is kept as a constant. The argument of perigee $\left(\omega_{\mathrm{p}}\right)$ moves in the orbital plane relatively slowly and, since it is highly correlated to the true anomaly $(f)$, it should also be kept as a constant (Westin and Forsgren, 2001). The motion of a satellite in orbit can be considered to be smooth and predictable, especially over the short period of time, in 
which one scene is acquired. The position and attitude of the satellite at a given time can be linearly related to the location of the satellite corresponding to the central line array. The change of the exterior orientation parameters has been approximated by different polynomial orders of time (first, second and third order). Using second-order polynomials on all exterior orientation parameters, allowing for some degree of nonlinear changes in the satellite's position and attitude (Orun and Natarajan, 1994). Since the viewing geometry of the sensor along the linear array is a central projection, it is only necessary to allow for changes in the along-track $(x)$ direction. The relationship between the EO parameters and time $t$ (or image $x$ coordinate) can be formulated as follows:

$$
\begin{aligned}
X_{\mathrm{i}} & =X_{o}+a_{1} x_{\mathrm{i}}+b_{1} x_{\mathrm{i}}^{2} \\
Y_{\mathrm{i}} & =Y_{o}+a_{2} x_{\mathrm{i}}+b_{2} x_{\mathrm{i}}^{2} \\
Z_{\mathrm{i}} & =Z_{o}+a_{3} x_{\mathrm{i}}+b_{3} x_{\mathrm{i}}^{2} \\
\kappa_{\mathrm{i}} & =\kappa_{o}+\kappa_{1} x_{\mathrm{i}}+\kappa_{2} x_{\mathrm{i}}^{2} \\
\varphi_{\mathrm{i}} & =\varphi_{o}+\varphi_{1} x_{\mathrm{i}}+\varphi_{2} x_{\mathrm{i}}^{2} \\
\omega_{\mathrm{i}} & =\omega_{o}+\omega_{1} x_{\mathrm{i}}+\omega_{2} x_{\mathrm{i}}^{2}
\end{aligned}
$$

Where;

$X_{\mathrm{i}}, Y_{\mathrm{i}}, Z_{i}, \kappa_{\mathrm{i}}, \varphi_{\mathrm{i}}, \omega_{\mathrm{i}}$ are the instantaneous exterior orientation parameters of line $i$;

$X_{o}, Y_{o}, Z_{o}$ are coordinates of the sensor position corresponding to the scene center;

$\omega_{0}, \varphi_{0}, \kappa_{\mathrm{o}}$ are the rotation angles corresponding to the scene center;

$a_{1}, a_{2}, a_{3}, b_{1}, b_{2}, b_{3}$ are the linear and quadratic rates of change of scanner location;

$\kappa_{1}, \varphi_{1}, \omega_{1}, \kappa_{2}, \varphi_{2}, \omega_{2}$ are the linear and quadratic rates of change of rotation angles;

$x_{\mathrm{i}}$ is the time difference between satellite positions (positive or negative) of line $i$ and the scene center.

The photogrammetric space resection formula (Equation 1) is expanded in order to include the effect of time dependent parameters, the dynamic space resection formula can be written for any image point (p) as follows (Farrag 1991):

$$
\left(\begin{array}{c}
\mathrm{x}(\mathrm{p}) \\
\mathrm{y}(\mathrm{p}) \\
-c
\end{array}\right)=\left(\begin{array}{c}
0 \\
\mathrm{y}(\mathrm{p}) \\
-c
\end{array}\right)=\mathrm{S} * \mathrm{R} *\left(\begin{array}{c}
\mathrm{X}_{\mathrm{p}}-\left(\mathrm{X}_{\mathrm{o}}+\mathrm{a}_{1} * x(\mathrm{p})+\mathrm{b}_{1} *(x(\mathrm{p}))^{2}\right) \\
\mathrm{Y}_{\mathrm{p}}-\left(\mathrm{Y}_{\mathrm{o}}+\mathrm{a}_{2} * x(\mathrm{p})+\mathrm{b}_{2} *(x(\mathrm{p}))^{2}\right) \\
\mathrm{Z}_{\mathrm{p}}-\left(\mathrm{Z}_{\mathrm{o}}+\mathrm{a}_{3} * x(\mathrm{p})+\mathrm{b}_{3} *(x(\mathrm{p}))^{2}\right)
\end{array}\right)
$$

Where:

$\mathrm{c}$ is the effective focal length

$\mathrm{S}$ is a scale factor;

$\mathrm{x}(\mathrm{p})$ is image coordinate of point (p) along track (line number).

$y(p)$ is image coordinate of point (p) across track (pixel number);

$\mathrm{X}_{\mathrm{o}}, \mathrm{Y}_{\mathrm{o}}$, and $\mathrm{Z}_{\mathrm{o}}$ are the coordinates of the perspective center corresponding to the center of the scene;

$\mathrm{X}_{\mathrm{p}}, \mathrm{Y}_{\mathrm{p}}$, and $\mathrm{Z}_{\mathrm{p}}$ are the ground coordinates of the same image point (p); and

$\mathrm{a}_{1} ; \mathrm{a}_{2}$; and $\mathrm{a}_{3}$ are linear rates of change in $\left(\mathrm{X}_{\mathrm{o}}, \mathrm{Y}_{\mathrm{o}}\right.$, and $\left.\mathrm{Z}_{\mathrm{o}}\right)$ coordinates respectively.

$\mathrm{b}_{1} ; \mathrm{b}_{2} ;$ and $\mathrm{b}_{3}$ are quadratic rates of change in $\left(\mathrm{X}_{\mathrm{o}}, \mathrm{Y}_{\mathrm{o}}\right.$, and $\left.\mathrm{Z}_{\mathrm{o}}\right)$ coordinates respectively.

$\mathrm{R}=\mathrm{M}(\mathrm{Q}) * \mathrm{M}(\mathrm{L}) * \mathrm{M}(\mathrm{O})$; where: 
$\mathrm{M}(\mathrm{O})$ is an orthogonal matrix as a function of reference rotation angles $\kappa_{\mathrm{o}}, \varphi_{\mathrm{o}}$ and $\omega_{\mathrm{o}}$, between the working and the image coordinate systems, corresponding to the scene center.

$\mathrm{M}(\mathrm{L})$ is an orthogonal matrix as a function of linear rates of change $\left(\kappa_{1}, \varphi_{1}\right.$ and $\left.\omega_{1}\right)$ in the reference rotation angles and the image line number $x(p)$.

$\mathrm{M}(\mathrm{Q})$ is an orthogonal matrix as a function of quadratic rates of change $\left(\kappa_{2}, \varphi_{2}\right.$ and $\left.\omega_{2}\right)$ in the reference rotation angles and the image line number $x(p)$.

Accordingly the dynamic space resection formula includes the following unknown exterior orientation parameters:

i- $\quad$ The coordinates of the reference position of the perspective center $\mathrm{X} 0, \mathrm{Y}_{0}$, and $\mathrm{Z}_{0}$ (corresponding to the center of scene).

ii- The attitude reference values $\left(\kappa_{\mathrm{o}} ; \varphi_{\mathrm{o}}\right.$; and $\left.\omega_{\mathrm{o}}\right)$.

iii- The linear rates of change $\left(\kappa_{1} ; \varphi_{1}\right.$; and $\left.\omega_{1}\right)$ of the attitude elements.

iv- The quadratic rates of change $\left(\kappa_{2} ; \varphi_{2} ;\right.$ and $\left.\omega_{2}\right)$ of the attitude elements.

$\mathrm{v}$ - Although the values of the linear and quadratic rates of change in the coordinates $\left(\mathrm{X}_{0}, \mathrm{Y}_{0}\right.$, and $\left.\mathrm{Z}_{0}\right)$ of the reference position can be determined as a function of the well defined earth rotation and satellite tracking speed, further corrections are given to these parameters during the solution. This will take care of random changes in the satellite tracking speed and this leads to six additional unknowns.

In this case, there are additional 12 unknown parameters to the regular 6 unknown parameters $\left(X_{o}, Y_{o}, Z_{o}, \omega_{0}, \varphi_{\mathrm{o}}, \kappa_{\mathrm{o}}\right)$ when compared to the frame camera. The initial approximation of the reference position coordinates and the corresponding orientation angles are determined from orbit geometry and the information provided with the original digital image. The linear and quadratic rates of change in the reference position coordinates and the linear rates of change in the orientation angles are computed as initial values from the known earth rotation and satellite tracking speed. The mathematical formulations of the exterior orientation parameters look so non-problematic. However, there is a major problem which the nature of the pushbroom sensor would cause. For instance, in the case of a second order polynomial approximation for the exterior orientation parameters, 18 unknowns cannot be solved in a single estimation procedure due to the correlations between the parameters (Ok and Turker, 2006, Orun and Natarajan, 1994). So the equations are linearized by using Taylor's series expansion. The test was done employing 12 parameters $\left(X_{o}, Y_{o}, Z_{o}, a_{l}\right.$, $\left.a_{2}, a_{3}, b_{1}, b_{2}, b_{3}, \omega_{0}, \varphi_{0}, \kappa_{0}\right) ; 15$ parameters $\left(X_{o}, Y_{o}, Z_{o}, a_{1}, a_{2}, a_{3}, b_{1}, b_{2}, b_{3}, \omega_{0}, \varphi_{0}, \kappa_{0}, \omega_{1}\right.$, $\left.\varphi_{1}, \kappa_{1}\right)$; and 18 parameters $\left(X_{o}, Y_{o}, Z_{o}, a_{1}, a_{2}, a_{3}, b_{1}, b_{2}, b_{3}, \omega_{0}, \varphi_{0}, \kappa_{0}, \omega_{1}, \varphi_{1}, \kappa_{1}, \omega_{2}, \varphi_{2}\right.$, $\left.\kappa_{2}\right)$.

\section{GENERATION OF DEM FROM TOPOGRAPHIC MAP 1:25000}

The use of a DEM is important for any environmental study of a region. It represents an important component (3D terrain representation) of maps and GIS databases and serves as a base for thematic applications (geologic, tectonic). The use of DEM is essential in case of orthoimage production. The applied methodology for obtaining a DEM depends on numerous parameters; these parameters include accuracy, time of production and cost components. Different methods have been used to collect DEM data in the applications which include Terrestrial topographical surveying, GPS 
supported observation, Photogrametric measurement techniques and digitizing the existing topographical map (Arzu and Metin, 2009). In recent years, many techniques have become popular for elevation data collection such as remote sensing images, Lidar "light detection and ranging" technology and Interferometric SAR (syntactic aperture radar) data. Stereo satellite images have disadvantages that they are expensive and it is difficult to acquire images which were corresponded with an objective region and time (Joon, et al. 2008). Topographic map is one of the most common and conventional method for representation of the elevations (Arzu and Metin, 2009).

For this study, the input data required to produce the DEM were obtained from topographic map of 1:25000 with contour intervals of $10 \mathrm{~m}$. The map contains also several spot heights distributed all over the map. First of all, the map sheet was scanned with optical resolution of $150 \times 150$ dpi so it was achieved in raster format. A number of control points were selected on the raster map and the original map sheet for transforming the raster map to spatial coordinate systems. In principle, the control points were selected on the corners and the center of the topographic map sheets. Affine coordinate transformation was used. In the next stage, the contour lines on the digital map were digitized using ERDAS imagines 8.4 software. Then the data obtained by digitizing the contour lines in addition to spot heights were utilized with Radial Basis Function (RBF) in Golden Software Surfer 9.0 program to generate regular DEM grid.

\section{ORTHOIMAGE GENERATION}

To generate the orthoimage, there are two steps, the first step is the determination of the image coordinates (in the original image plane) corresponding to each DEM grid point that was generated with the proposed method. The second step is computing a gray value for every pixel after being located in the original image plane. These steps cannot use Equation (4) directly to determine the image coordinates of the DEM grid points because we do not know exactly which scan-line orientation parameters can be used. This can be overcome by applying an iterative approach as follows (Farrag 1996):

i- Determine approximate position of the DEM grid points on the original image plane, i.e. the pixel No. and the scan-line No. which pass by each DEM grid point. This can be achieved by applying a second order two dimensional polynomial transformation based on the same control points which were used to determine the orientation parameters (Equation 4). This step gives the approximate image points (i.e. scan-lines $\mathrm{x}_{\mathrm{i}}$, pixel position $\mathrm{y}_{\mathrm{i}}$ ) for each DEM grid point (i).

ii- Use the computed $x_{i}$ in order to compute the orientation parameters corresponding to these image coordinates. These parameters are (Equation 4) satellite instantaneous position and elements of matrices M (L) \& M (Q).

iii- Substitute the computed orientation parameters for the corresponding parameters in the collinearity formula (Equation 4) and compute new image coordinates $\left(\mathrm{x}_{\mathrm{i}}\right.$ and $\left.\mathrm{y}_{\mathrm{i}}\right)$. 
Repeat steps (ii) using the new image coordinates and then repeat step (iii). This iteration can continue until the difference between the new and the previous computed values of image coordinates becomes less than a specified threshold ( 0.25 pixel size is used as threshold in our test). As a result of applying the iterative approach given above, the image coordinates corresponding to each DEM grid point will be determined. In the second step the gray value can be computed by one of these methods: the Nearest Neighbor or the Bilinear Interpolation. This process is sequentially repeated for all DEM grid points, to produce the orthoimage. Figure 6 shows Assiut orthoimage generated from Egypt Sat-1 image.

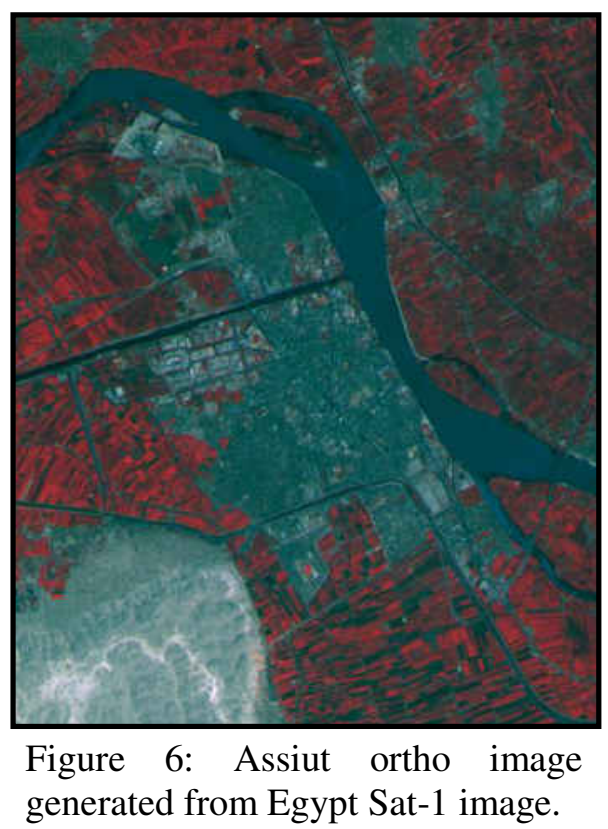

\section{EXPERIMENTAL RESULTS}

The study area corresponds to a window of Egypt Sat-1 satellite image range from pixel No. $=120$ to pixel No. $=2043$ and line No. $=366$ to line No. $=2481$. A set of 26 well defined and distributed ground control points (GCPs) and check points were collected. The coordinates of these points were determined from the 1:25,000 map and field observation applying Global Positioning System (GPS). The GCPs are identified over the raw image and chosen according to some natural and man-made details. GCPs and check points were taken from the topographic maps when exists difficulty in using GPS in some places such as mountainous area.

Three different sets of tests were carried out, representing different combinations of control and check points. The result of test model employing 12 parameters, 15 parameters and 18 parameters was compared with the result of secondorder polynomial transformation. The total number of unknown exterior orientation parameters is 18; accordingly the minimum number of required control points is nine. Root Mean Square (RMS) of the residuals at both control and check points are computed and used in order to compare the results as shown in table 1 and graphically represented in figure 7.

As indicated in table 1 and figure 7, using the rigorous algorithm with $(12,15$ and 18 parameters) gives lower RMS at control points and lower RMS at check points than the second-order polynomial. Including the linear and quadratic terms of the rotation angles in the rigorous algorithm with 15 and 18 parameters gives improvement in residuals at control points. The method of rigorous algorithm with 12 parameters gives better results than 15 and 18 parameters at error of check points in this study and that point to the stability of rotation angles of the platform and the sensor over the period of imaging the image. The accuracy for the check points in the generated orthoimage, has RMS of $5.5 \mathrm{~m}$ in $\mathrm{X}, 3.5 \mathrm{~m}$ in $\mathrm{Y}$ and $6.5 \mathrm{~m}$ in XY. The above results 
shows, that the developed model for orthoimage generation for Egypt Sat-1 image works properly and within one pixel.

\section{TABLE 1: RMS of error in X, Y and XY for GCP and check points using different number of parameters and compared with second-order}

polynomial

\begin{tabular}{|c|c|c|c|c|c|c|c|c|c|}
\hline \multirow{2}{*}{\multicolumn{2}{|c|}{ Restitution algorithm }} & \multirow{2}{*}{$\begin{array}{l}\text { Number of } \\
\text { control } \\
\text { points }\end{array}$} & \multicolumn{3}{|c|}{$\begin{array}{l}\text { RMS at control } \\
\text { points }(\mathbf{m})\end{array}$} & \multirow{2}{*}{$\begin{array}{c}\text { Number } \\
\text { of check } \\
\text { points }\end{array}$} & \multicolumn{3}{|c|}{$\begin{array}{l}\text { RMS at check } \\
\text { points }(\mathbf{m})\end{array}$} \\
\hline & & & $\mathbf{X}$ & $\mathbf{Y}$ & XY & & $\mathbf{X}$ & $\mathbf{Y}$ & $\mathbf{X Y}$ \\
\hline \multirow{3}{*}{$\begin{array}{c}\text { Rigorous } \\
\text { algorithm } \\
\text { with }\end{array}$} & 12 parameters & \multirow{4}{*}{9} & 2.7 & 5.3 & 5.9 & \multirow{4}{*}{17} & 6.6 & 8.5 & 10.8 \\
\hline & 15 parameters & & 3.0 & 3.0 & 4.3 & & 13.9 & 8.6 & 16.3 \\
\hline & 18 parameters & & 0 & 0 & 0 & & 11.2 & 12.5 & 16.8 \\
\hline \multicolumn{2}{|c|}{$2^{\text {nd }}$ order polynomial } & & 14.5 & 6.3 & 15.8 & & 8.8 & 5.8 & 10.5 \\
\hline Rigorous & 12 parameters & \multirow{4}{*}{14} & 5.7 & 7.6 & 9.5 & \multirow{4}{*}{12} & 4.4 & 5.1 & 6.8 \\
\hline algorithm & 15 parameters & & 5.6 & 7.0 & 8.9 & & 5.5 & 4.9 & 7.4 \\
\hline with & 18 parameters & & 3.6 & 5.2 & 6.3 & & 5.6 & 7.3 & 9.2 \\
\hline \multicolumn{2}{|c|}{$2^{\text {nd }}$ order polynomial } & & 11.6 & 5.1 & 12.7 & & 9.5 & 7.5 & 12.1 \\
\hline \multirow{3}{*}{$\begin{array}{c}\text { Rigorous } \\
\text { algorithm } \\
\text { with }\end{array}$} & 12 parameters & \multirow{4}{*}{20} & 6.0 & 7.1 & 9.3 & \multirow{4}{*}{6} & 5.1 & 4.8 & 7.0 \\
\hline & 15 parameters & & 6.1 & 7.1 & 9.3 & & 5.5 & 3.5 & 6.5 \\
\hline & 18 parameters & & 4.7 & 6.2 & 7.8 & & 6.1 & 5.1 & 7.9 \\
\hline \multicolumn{2}{|c|}{$2^{\text {nd }}$ order polynomial } & & 10.4 & 5.5 & 11.8 & & 9.6 & 6.0 & 11.3 \\
\hline \multirow{3}{*}{$\begin{array}{c}\text { Rigorous } \\
\text { algorithm } \\
\text { with }\end{array}$} & 12 parameters & \multirow{4}{*}{26} & 5.7 & 7.6 & 9.5 & & - & - & - \\
\hline & 15 parameters & & 5.7 & 7.5 & 9.4 & & - & - & - \\
\hline & 18 parameters & & 5.0 & 6.1 & 7.9 & & - & - & - \\
\hline \multicolumn{2}{|c|}{$2^{\text {nd }}$ order polynomial } & & 10.5 & 5.4 & 11.8 & & - & - & - \\
\hline
\end{tabular}



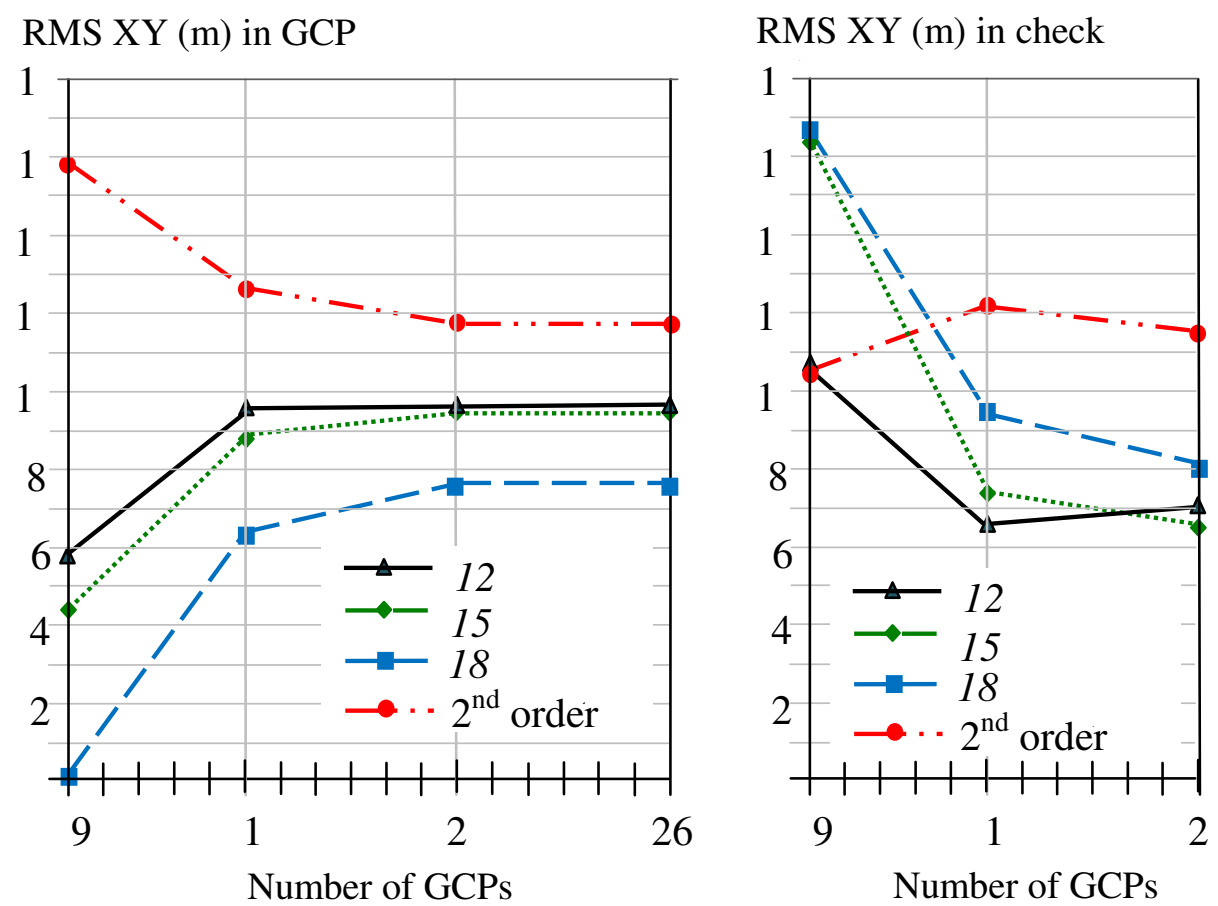

Figure 7: RMS in XY for GCP and check points.

\section{CONCLUSIONS}

In this research, orthoimage is efficiently generated from Egypt Sat-1 image. The developed mathematical model can serve as a base geometric model for Egypt Sat-1 sensor and can be characterized for future missions. The physical model for the geometric restitution was superior to second order polynomial. This was evidenced from the lower RMSE in the computed coordinates of control points and check points. The accuracy of orthoimage is $5.5 \mathrm{~m}$ in $\mathrm{X}, 3.5 \mathrm{~m}$ in $\mathrm{Y}$ and $6.5 \mathrm{~m}$ in XY. The results from testing the method demonstrate the possibility to orthorectify Egypt Sat-1 image to sub-pixel accuracy. Orthoimages generated from Egypt Sat-1 satellite images can contribute significantly to map revision, image map production and to GIS applications.

\section{REFERENCES}

1. Arzu, S., Metin, S., 2009 "Digital Elevation Model Production from Scanned Topographic Contour Maps Via Thin Plate Spline Interpolation" The Arabian Journal for Science and Engineering, Volume 34, Number 1A, Pp. 121-134

2. Ayman, H., Ashraf, K., 2009. "Integration of Misrsat-1 and SPOT-2 Data for Quantitative Change Detection Applications". The International Congress for Global Science and Technology (ICGST) - International Journal on Graphics, Vision and Image Processing (GVIP) Journal, Volume 9, Issue 5.

3. Farrag, A., 1991. "Map Updating Using Digital Techniques with Emphasis on SPOT Images". PhD Dissertation, Faculty of Engineering., Assiut University Egypt. 
4. Farrag, A., 1996. "The Influence of Terrain Type and Density of DEM on the Geometric Quality of Satellite Orthoimages”, Archives ISPRS'96, Vol. XXXI, Part B4, pp. 246-251, Vienne, Autriche.

5. Fritsch, D., and Stallmann, D., 2000. "Rigorous Photogrammetric Processing of High Resolution Satellite Imagery". In: IAPRS Vol. XXXIII, Part B1, Comm. I, pp. 313-321, ISPRS Congress, Amsterdam.

6. Giannone, f., 2006. "A rigorous model for High Resolution Satellite Imagery Orientation". PhD Thesis University of Rome "La Sapienza" Faculty of Engineering

7. Joon, M., Hee, C., Joon, K., 2008. "Evaluation of Possibility of Ortho Imagery Production Using SPOT 5 Single Image" The International Archives of the Photogrammetry, Remote Sensing and Spatial Information Sciences. Vol. XXXVII. Part B4. Beijing.

8. Kim, T., and Dowman, I., 2006. "Comparison of Two Physical Sensor Models for Satellite Images: Position-Rotation Model and Orbit-Attitude Model" The Photogrammetric Record, 21(114), pp. 110-123.

9. kratky, V., 1987. "Rigorous Stereophotogrammetric Treatment of SPOT Images" In: Proceedings of the SPOT-1 : Image Utilization, Assessment, Results Symposium, CNES, Paris, France, pp; 1281-1288.

10. Li, R., 1998. "Potential of High-Resolution Satellite Imagery for National Mapping Products, Photogrammetric Engineering \& Remote Sensing, 64(2): pp.1165-1169.

11. NARSS., 2011. "Page Title: Egyptian Space Program" www.narss.sci.eg/Capabilities.aspx, (last date accessed: February. 25, 2011).

12. Orun, A., and Natarajan, K., 1994. "A Modified Bundle Adjustment Software for SPOT Imagery and Photography" Photogrammetric Engineering and Remote Sensing, Vol. 60, No. 12, pp. 1431-1437.

13. Ok, A. and Turker, M. 2006. "Comparison of Different Mathematical Models on The Accuracy of The Orthorectification of ASTER Imagery" ISPRS Workshop, Topographic Mapping from Space (with Special Emphasis on Small Satellites), February 14-16, Ankara, Turkey,

14. Ok, A., and Turker, M., 2007. "Geometric Calibration and Orthorectification of Bilsat-1 Imagery" Proceedings of the ASPRS 2007 Annual Conference, May 7-11, Tampa, Florida, USA.

15. Poli, D., 2002. "General Model for Airborne and Spaceborne Linear Array Sensors" International Archives of Photogrammetry, Remote Sensing and Spatial Information Sciences, Denver, USA, 10-15 november, Vol. 33, Part B1, pp.177-182.

16. Toutin, T., 2004. "Geometric processing of remote sensing images: models, algorithms and methods" Int. J. Remote Sens. 25, pp. 1893-1924.

17. Valadan, M., and Petrie, G., 1998. "Mathematical Modelling and Accuracy Testing of SPOT Level 1B Stereopairs" Photogrammetric Record, 16(91): pp.67-82

18. Westin, T., and Forsgren, J., 2001. "Orthorectification of EROS A1 Images". IEEE/ISPRS Joint Workshop on" Remote Sensing and Data Fusion Over Urban Areas", Rome, Nov. 8-9, 2001. 
19. Zhou, G., and Li, R., 2000. “Accuracy Evaluation of Ground Points from IKONOS High- Resolution Satellite Imagery" Photogrammetric Engineering \& Remote Sensing, 66(9): pp. 1103-1112.

\section{ACKNOWLEDGEMENTS}

The authors are grateful to Dr Matar Ali Matar the executive manager of the Egyptian space program for his help during the image data acquisition and handling. His help is gratefully appreciated.

\section{نموذج جديد لتقويم مرئيات القمر الصناعي المصري الأول}

yasser_g_m@yahoo.com dr_farrag@yahoo.com a.abdelhafiz@yahoo.com a.m.whd@aun.edu.eg

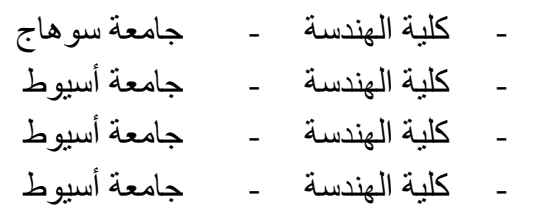$$
\text { - - مدرس مساعد }
$$$$
\text { أستاذ المساحة مدياعة }
$$$$
\text { م. ياسـر جابر }
$$$$
\text { مدرس المساحة }
$$

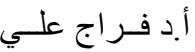$$
\text { أستاذ المساحة المنياحة }
$$

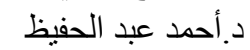

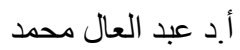

تعتمد دقة البيانات التي يمكن استخراجها من المرئيات المصححة (Orthoimages) على دقة البيانات التي يتم إدخالها وكذلك على دقة طريقة التصحيح المستخدمة، حيث تحتوى مرئيات الأقمار الصناعية عموما على تشوهات هندسية مما يؤدي الي عدم أخذ قياسات منها بشكل مباشر • وتتراوح مصادر هذه التشوهات بين انحناء سطح الأرض ودورانها، اتجاه وارتفاع القمر الصناعي، خصائص المسنتعر المستخدم وبعض العوامل الأخرى لترى مثل الإزاحة بفعل اختلاف التضاريس. ولإنتاج مرئيات مصححه (Orthoimages) يلزم ذللك نموذج ارتفاعات رقمية للمنطقة بدقة كافية وكذلك نموذج تصحيح دقيق لربط إحداثيات المرئية بإحداثيات الطبيعة. الغرض من هذا لهات

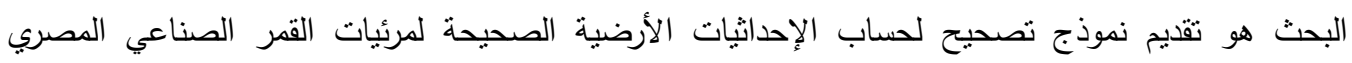
Egypt Sat-1 من أجل أنتاج مرئيات مصححة (Orthoimages). تم عمل الدراسة باستخدام مرئية ملتقطة بواسطة Egypt Sat-1 عام 2009 نوضح مدينة أسيوط وما حولها و كذلك خريطة طبوغرافية للمنطقة مقياس 1 تونية 25000 عام 1991 تم استخدامها لعمل نموذج ارتفاعات رقمية للمنطقة. و قد بينت الدراسة أمكانية تصحيح المرئية بدقة كافية بحيث يمكن استخدام المرئية المصححة في نطبيقات مختلفة مثل مراجعة وإنتاج الخرائط وكذلك في نطبيقات نظم المعلومات الجغرافية. 